\title{
Ultrasonographic assessment of renal length in 310 Turkish children in the Eastern Anatolia region
}

\author{
M Özdikici, $\mathrm{MD}, \mathrm{PhD}$ \\ Department of Radiology, Bakirköy Training and Research Hospital, Istanbul, Turkey \\ Corresponding author: $M$ Özdikici (meteozdikici@hotmail.com)
}

\begin{abstract}
Background. Kidney size varies with age in children. It is therefore clear that a standardisation of measurements by age group is required. Objectives. To determine the normal renal length of healthy children in the Eastern Anatolia region of Turkey using ultrasonography and to study the relationship between renal length and sex, age, body height and weight, repsectively.

Methods. A retrospective study of 310 children aged 0 - 16 years (150 girls and 160 boys) was performed. The children were divided into 11 age groups. Scanning was performed with a $3.5 \mathrm{MHz}$ ultrasound probe in the supine position. The ultrasonographic appearance of the kidneys we measured was normal. The maximum length of each kidney was measured. The renal length was correlated with somatic parameters including age, body height and weight. Regression equations were derived for each pair of dependent and independent variables. Results. No difference was found between the renal lengths of the boys and girls $(p>0.05)$. The mean left renal length was greater than the right renal length, and this difference was statistically significant $(p<0.001)$. Renal length showed the strongest correlation with body height $(r=0.966$ and $r=0.958$ for the right and left kidneys, respectively; $p<0.001)$.

Conclusion. It is important to know the limits of kidney size on ultrasound examination. We found that renal length showed the strongest correlation with body height. The renal length can be calculated easily by deriving a linear regression equation. We hope that our study will be useful in daily routine ultrasonography.
\end{abstract}

S Afr J Child Health 2018;12(1):34-37. DOI:10.7196/SAJCH.2018.v12i1.1405

The kidneys are paired organs, placed symmetrically retroperitoneal in the abdominal region. The size of the kidney varies with age and there may also be racial differences in renal length (RL). It is important to have a reliable reference to kidney size in children ${ }^{[1-6]}$ as many diseases lead to an increase or decrease in renal size.

Ultrasonography is a non-invasive modality that can be used to measure RL. ${ }^{[2]}$ The purpose of the study was to determine the relationship between RL and age, body height and weight, respectively, in healthy Turkish children $(0-16$ years old $)$ in the Eastern Anatolia region using ultrasonography.

\section{Methods}

This retrospective study was approved by the Erzurum State Hospital Ethics Committee (ref. no. Erzurum BEAH KAEK 2016/12-114) and included children who were referred to the Radiology Department at Erzurum State Hospital in Istanbul, Turkey, for ultrasonography for any reason unrelated to the kidneys. Over the course of $\sim 2$ years, all normal cases were selected for inclusion in the study.

Ultrasonography was performed using an ultrasound unit with a 3.5 MHz convex transducer. RL measurements were performed in the sagittal plane, with children in the supine position. The distance between the top and bottom poles of both kidneys was measured (Fig. 1).

Body parameters such as gender, age, body height, and weight were determined and the data were divided into 11 age groups. Measurements were analysed separately for the right and left kidneys, within each age group. Data were analysed using SPSS version 15.0 (SPSS Inc., USA). Pearson's correlation coefficients and simple regression analysis were used.

\section{Results}

A total of 310 children (150 girls and 160 boys) aged 0 - 16 years were included in the study. There was no significant difference in RL between the sexes $(p>0.05)$ and therefore all data were rearranged in 11 different age groups regardless of gender. The descriptive analysis of the right and left RL (mean, median, minimum and maximum

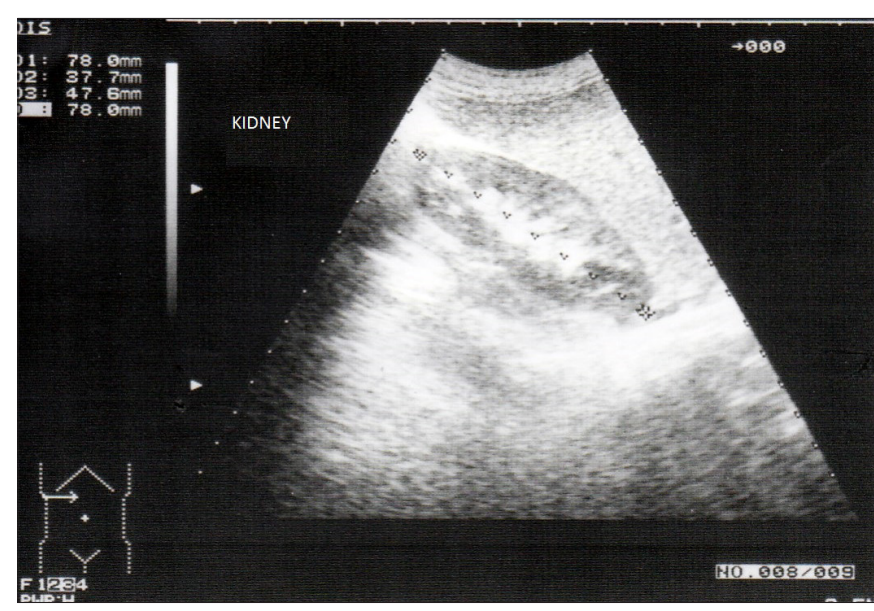

Fig. 1. Measurement of the left renal length from the upper pole to the lower pole.

values; standard deviations; 10 th and 90th percentile values; and 95\% confidence interval (CI) values) are shown in Tables 1 and 2.

The left RL was significantly larger than the right $\mathrm{RL}(p<0.001)$. Correlations of the right and left RL with body height are shown in Figs 2 and 3. Percentile curves of the right and left RL v. age group are shown in Fig. 4.

The RL has been correlated with the children's age (right, $r=0.930$; left, $r=0.913$ ), and weight (right, $r=0.934$; left, $r=0.917$ ). The length of both the right $(r=0.966)$ and the left $(r=0.958)$ kidneys showed the strongest correlation with body height.

Linear regression equations for predicting a variable (renal length) from independent variables (height and weight) were obtained as follows:

Right renal length $(\mathrm{mm})=25.473+0.438 \times$ height $(\mathrm{cm})$; and 50.240 $+0.944 \times$ weight $(\mathrm{kg})$

Left renal length $(\mathrm{mm})=29.196+0.435 \times$ height $(\mathrm{cm})$; and 53.984 $+0.929 \times$ weight $(\mathrm{kg})$ 
Table 1. Right renal length correlation with age by ultrasonography in healthy children $(N=310)$

\begin{tabular}{|c|c|c|c|c|c|c|c|}
\hline & & \multicolumn{6}{|c|}{ Right renal length (mm) } \\
\hline & & $n(\%)$ & Mean (SD) & Median (IQR) & 10th percentile & 90th percentile & $95 \% \mathrm{CI}$ for the mean \\
\hline 1 & $0-<3$ mo & $21(6.77)$ & $49(8)$ & $47(38-65)$ & 38 & 64 & $45-52$ \\
\hline 2 & $3-<6$ mo & $24(7.74)$ & $52(8)$ & $53(40-65)$ & 42 & 64 & $49-56$ \\
\hline 3 & $6-<12 \mathrm{mo}$ & $24(7.74)$ & $57(5)$ & $57(50-68)$ & 52 & 65 & $56-61$ \\
\hline 4 & $1-<2 y$ & $30(9.67)$ & $61(4)$ & $61(54-69)$ & 55 & 67 & $59-62$ \\
\hline 5 & $2-<4 y$ & $27(8.70)$ & $67(6)$ & $66(55-77)$ & 58 & 73 & $64-69$ \\
\hline 6 & $4-<6 y$ & $27(8.70)$ & $73(6)$ & $75(61-83)$ & 63 & 81 & $71-76$ \\
\hline 7 & $6-<8 y$ & $31(10.0)$ & $79(6)$ & $79(67-93)$ & 72 & 91 & $77-82$ \\
\hline 8 & $8-<10 y$ & $26(8.38)$ & $83(7)$ & $83(71-97)$ & 73 & 94 & $77-83$ \\
\hline 9 & $10-<12 y$ & $27(8.70)$ & $88(6)$ & $87(80-102)$ & 81 & 99 & $86-91$ \\
\hline 10 & $12-<14 y$ & $38(12.25)$ & $94(6)$ & $94(82-104)$ & 85 & 101 & $91-96$ \\
\hline 11 & $14-<16 y$ & 35 (11.29) & $97(8)$ & $100(82-108)$ & 87 & 106 & $94-100$ \\
\hline
\end{tabular}

Table 2. Left renal length correlation with age by ultrasonography in healthy children $(N=310)$

\begin{tabular}{|c|c|c|c|c|c|c|c|}
\hline & & \multirow[b]{2}{*}{$n(\%)$} & \multicolumn{5}{|c|}{ Left renal length $(\mathrm{mm})$} \\
\hline & & & Mean (SD) & Median (IQR) & 10th percentile & 90th percentile & $95 \% \mathrm{CI}$ for the mean \\
\hline 1 & $0-<3$ mo & $21(6.77)$ & $52(8)$ & $51(38-65)$ & 40 & 65 & $48-55$ \\
\hline 2 & $3-<6 \mathrm{mo}$ & $24(7.74)$ & $56(7)$ & $56(40-65)$ & 46 & 65 & $53-59$ \\
\hline 3 & $6-<12 \mathrm{mo}$ & $24(7.74)$ & $61(4)$ & $60(50-68)$ & 55 & 67 & $59-62$ \\
\hline 4 & $1-<2 y$ & $30(9.67)$ & $65(5)$ & $64(54-69)$ & 58 & 73 & $62-67$ \\
\hline 5 & $2-<4 y$ & $27(8.70)$ & $71(5)$ & $71(55-77)$ & 63 & 76 & $69-72$ \\
\hline 6 & $4-<6 y$ & $27(8.70)$ & $77(7)$ & $76(61-83)$ & 67 & 86 & $75-80$ \\
\hline 7 & $6-<8 y$ & $31(10.00)$ & $83(7)$ & $84(67-93)$ & 73 & 93 & $81-86$ \\
\hline 8 & $8-<10 y$ & $26(8.38)$ & $86(7)$ & $87(71-97)$ & 75 & 97 & $81-87$ \\
\hline 9 & $10-<12 y$ & $27(8.70)$ & $92(6)$ & $93(80-102)$ & 82 & 100 & $89-94$ \\
\hline 10 & $12-<14 y$ & $38(12.25)$ & $97(8)$ & $97(82-104)$ & 84 & 107 & 94 - 99 \\
\hline 11 & $14-<16 y$ & 35 (11.29) & 99 (9) & $98(82-108)$ & 86 & 113 & $96-102$ \\
\hline
\end{tabular}

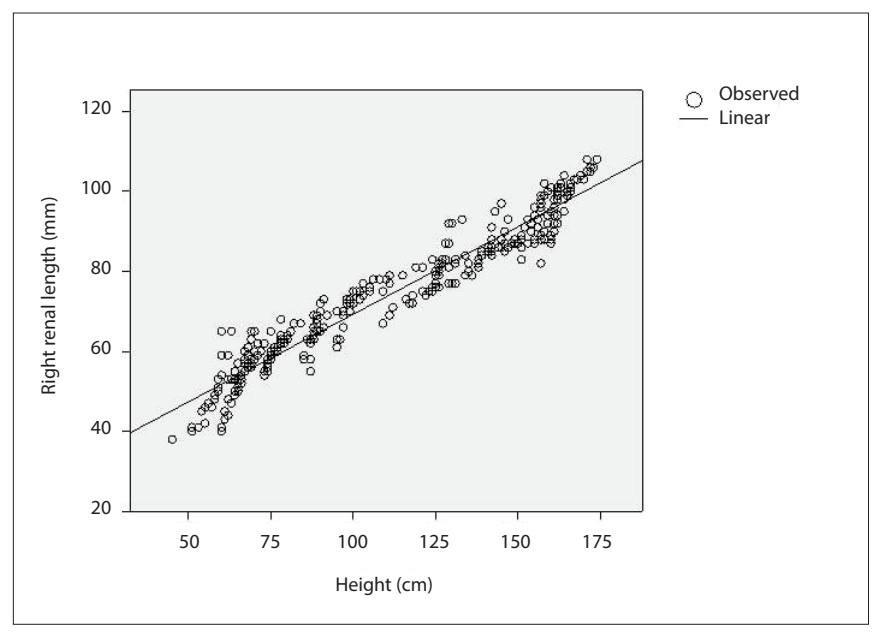

Fig. 2. Correlation curve of right renal length with body height. $(\mathrm{mm}=$ millimetres; $\mathrm{cm}=$ centimetres. $)$

\section{Discussion}

Renal diseases can lead to changes in kidney size and therefore knowing the normal limits of the kidney size of healthy children would be useful to distinguish abnormal conditions. It is also important to note that body height and weight may vary with ethnicity. ${ }^{[1,7]}$ Although there are numerous studies in the literature related to the kidney size of children, there are no data related to

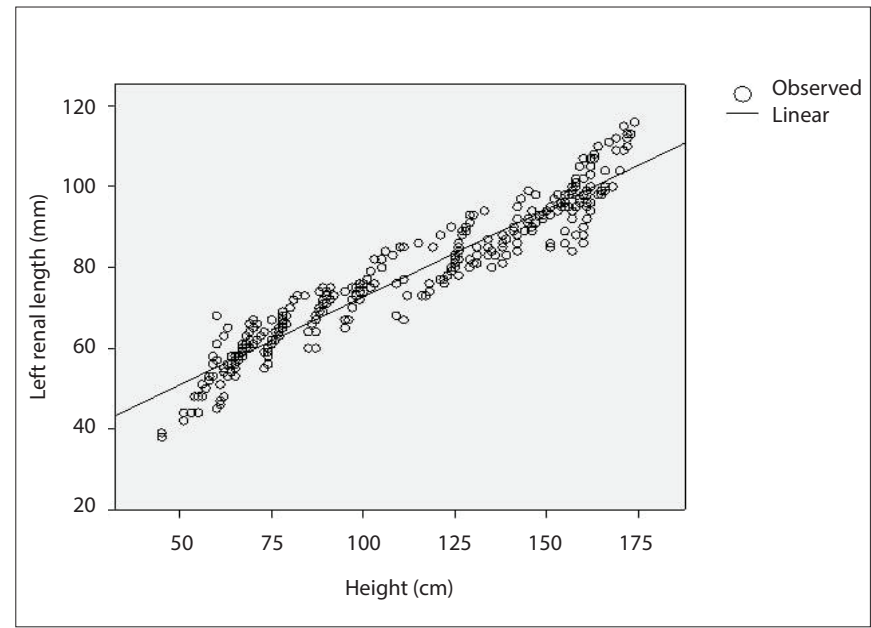

Fig. 3. Correlation curve of left renal length with body height. $(\mathrm{mm}=$ millimetres; $\mathrm{cm}=$ centimetres.)

children in the Eastern Anatolia region of Turkey. Our aim was to determine the normal standards of kidney sizes of Turkish children living in the Eastern Anatolia region.

Ultrasonography is the most widely used imaging method in routine practice and does not expose patients to ionising radiation. Ultrasonographic examination can be performed in the lateral decubitus, supine and prone positions. ${ }^{[4-6]}$ Our subjects were placed 
in the supine position for measurement of the distance between the upper and lower poles of both kidneys.

There is no consensus on which measurement parameter to use when evaluating kidney size. The assessment of kidney volume is time-consuming and impractical and as a number of previous studies have shown that RL correlates better with body parameters, we chose to compare RL with age, body height and weight, which was the easiest and most practical approach for us. ${ }^{[1,7-10]}$

Some studies found a linear relationship between RL and body height. They observed that the increase in the RL is much more rapid during the first years of life. ${ }^{[7-9,11,12]}$ The results of our study were in accordance with the findings of those studies.

There were discrepancies in sizes between the right and the left kidney. ${ }^{[10-13]}$ In our study, the left kidney was significantly larger
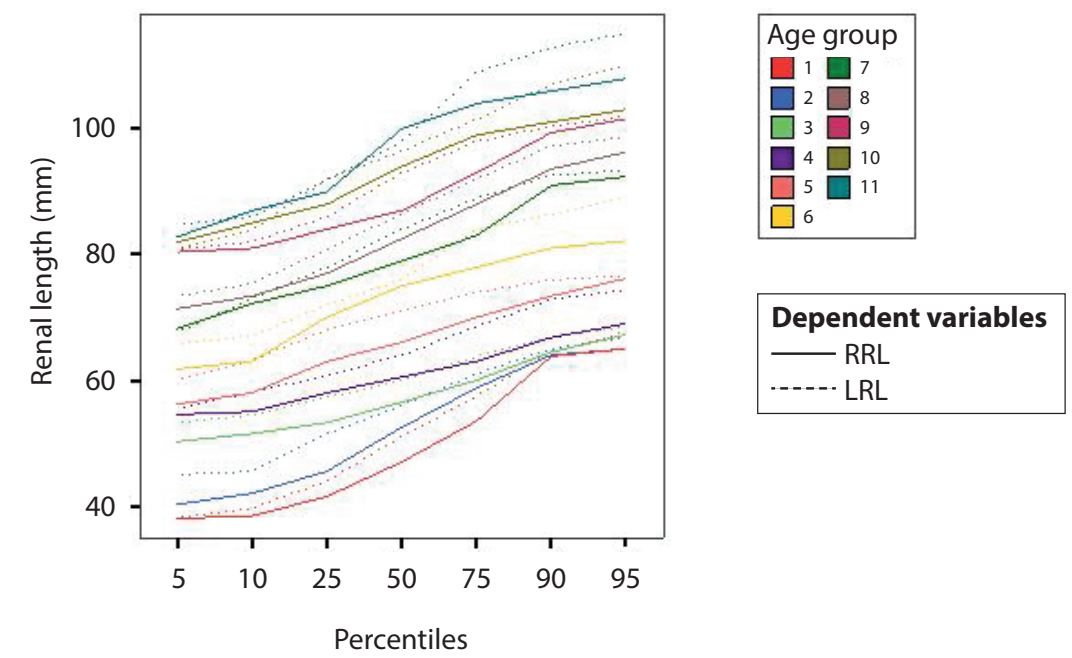

Fig. 4. Percentile curves of the right and left renal length $v$. age group. $(R R L=$ right renal length; $m m=$ millimetres; $L R L=$ left renal length.) than the right kidney $(p<0.001)$. For this reason, the size of both kidneys should be measured separately.

Some studies suggest that girls have smaller kidneys, while other studies indicate no differences in renal size between the genders. ${ }^{[7,-13]}$ In our study, there were no significant differences in RL with respect to gender $(p>0.05)$, which was not a determining factor of organ size within this age group.

Table 3 compares the data of our study with those of Konus et al..$^{[9]}$ and Otiv et al. ${ }^{[11]}$ As the age groups were different in those studies, we attempted to align the groups as closely as possible. Data from our study and that of Konuş et al. ${ }^{[9]}$ differed owing to the fact that data were collected from different regions in Turkey.

\section{Conclusion}

The present study showed that the best correlation was between RL and body height. Both should be measured separately, as there may be a size difference between the right and left kidneys. It was also found that there was no difference between the genders in terms of kidney size. We have tabulated the correlation of age with kidney length in this report and believe that these tables can be used in radiology clinics to assess conditions that lead to changes in renal size. We have also built the prediction models of RL (mm)

Table 3. Mean renal length $(\mathrm{mm})$ according to age group in different studies

\begin{tabular}{|c|c|c|c|c|c|c|c|}
\hline Age $^{*}$ & Mean $\mathrm{RL}^{*}$ & Age $(\mathrm{mo})^{\dagger}$ & R-Mean $\mathbf{R L}^{\dagger}$ & L-Mean $\mathbf{R L}^{\dagger}$ & Age $^{\ddagger}$ & R-Mean RL ${ }^{\ddagger}$ & L-Mean RL \\
\hline $1 \mathrm{mo}$ & 43 & $1-3$ & 50 & 50 & $0-<3$ mo & 49 & 52 \\
\hline $3 \mathrm{mo}$ & 47 & $4-6$ & 53 & 56 & & & \\
\hline $6 \mathrm{mo}$ & 55 & $7-9$ & 59 & 61 & $3-<6 \mathrm{mo}$ & 52 & 56 \\
\hline $9 \mathrm{mo}$ & 56 & & & & $6-<12 \mathrm{mo}$ & 57 & 61 \\
\hline $1 y$ & 57 & $12-30$ & 61 & 66 & $1-<2 y$ & 61 & 65 \\
\hline $2 y$ & 61 & & & & $2-<4 y$ & 67 & 71 \\
\hline $3 y$ & 67 & $36-59$ & 67 & 71 & & & \\
\hline $4 y$ & 68 & & & & $4-<6 y$ & 73 & 77 \\
\hline $5 y$ & 67 & $60-83$ & 74 & 79 & & & \\
\hline $6 y$ & 67 & & & & $6-<8 y$ & 79 & 83 \\
\hline $7 y$ & 72 & $84-107$ & 80 & 84 & & & \\
\hline $8 y$ & 76 & & & & $8-<10 y$ & 83 & 86 \\
\hline $9 y$ & 80 & $108-131$ & 80 & 84 & & & \\
\hline $10 \mathrm{y}$ & 80 & & & & $10-<12 y$ & 88 & 92 \\
\hline $11 \mathrm{y}$ & 85 & $132-155$ & 89 & 91 & & & \\
\hline \multirow[t]{3}{*}{$12 \mathrm{y}$} & 86 & & & & $12-<14 y$ & 94 & 97 \\
\hline & & $156-179$ & 94 & 96 & & & \\
\hline & & $180-200$ & 92 & 99 & $14-<16 y$ & 97 & 99 \\
\hline \multicolumn{8}{|c|}{$\begin{array}{l}\text { mo = months; } \mathrm{RL}=\text { renal length; } \mathrm{R}=\text { right } \mathrm{L}=\text { left } \mathrm{y}=\text { years. } \\
{ }^{*} \mathrm{Otiv} \text { et al. }\end{array}$} \\
\hline
\end{tabular}


according to body height $(\mathrm{cm})$ and weight $(\mathrm{kg})$ as an alternative method for radiologists and paediatricians to assess changes in renal size.

\section{Acknowledgements. None.}

Author contributions. Sole author.

Funding. None.

Conflicts of interest. None.

1. Rosenbaum DM, Korngold E, Teele RL. Sonographic assessment of renal length in normal children. Am J Roentgenol 1983;142:467-469. https://doi. org/10.2214/ajr.142.3.467

2. Abdulla AA. Ultrasonographic measurements of kidney dimensions of 109 Filipinos in South Luzon - a descriptive study. Acta Medica Philippina 2010;44(3):35-38.

3. Kadioglu A. Renal measurements, including length, parenchymal thickness, and medullary pyramid thickness, in healthy children: What are the normative ultrasound values? Am J Roentgenol 2010;194:509-515. https://doi. org/10.2214/AJR.09.2986

4. Larson DB, Meyers ML, O'Hara SM. Reliability of renal length measurements made with ultrasound compared with measurements from helical CT multiplanar reformat images. Am J Roentgenol 2011;196(5):592-597. https:// doi.org/10.2214/AJR.10.5486

5. Achim OF, Veștemean IL. Ultrasound relation between the dimensions of the spleen and left kidney in children. Acta Medica Transilvanica 2010;2(4):251-252.

6. Eze CU, Agwu KK, Ezeasor DN, Agwuna KK, Aronu AE. Sonographic determination of spleen to left kidney ratio among Igbo school age children of south east Nigeria. African Health Sci 2014;14(1):246-254. https://doi. org/10.4314/ahs.v14i1.38
7. Gavela T, Bayle MS, Mardones GG, Gallego S, Martínez-Pérez J, Pintado MT. Ultrasonographic study of kidney size in children. Nefrologia 2006;26:325-329.

8. Kim JH, Kim MJ, Lim SH, Kim J, Lee MJ. Length and volume of morphologically normal kidneys in Korean children: Ultrasound measurement and estimation using body size. Korean J Radiol 2013;14(4):677-682. https://doi.org/10.3348/ kjr.2013.14.4.677

9. Konus OL, Ozdemir A, Akkaya A, Erbas G, Celik H, Isik S. Normal liver, spleen, and kidney dimensions in neonates, infants, and children: Evaluation with sonography. Am J Roentgenol 1998;171(6):1693-1698. https://doi.org/10.2214/ ajr.171.6.9843315

10. Safak AA, Simsek E, Bahcebasi T. Sonographic assessment of the normal limits and percentile curves of liver, spleen, and kidney dimensions in healthy school-aged children. J Ultrasound Med 2005;24(10):1359-1364. https://doi. org/10.7863/jum.2005.24.10.1359

11. Otiv A, Mehta K, Ali U, Nadkarni M. Sonographic measurement of renal size in normal Indian children. Indian Pediatrics 2012;49:533-536. https://doi. org/10.1007/s13312-012-0120-7

12. Park CW, Yu N, Yun SW, et al. Measurement and estimation of renal size by computed tomography in Korean children. J Korean Med Sci 2017;32(3):448456. https://doi.org/10.3346/jkms.2017.32.3.448

13. Sultana S, Rahman S, Basak BK, Afza NS, Hossain N, Ferdaus S. Determination of kidney length and volume by ultrasound in 100 term Bangladeshi newborns. Bangladesh J Child Health 2012;36(1):26-29. https://doi.org/10.3329/bjch. v36i1.13032

Accepted 7 August 2017. 